\title{
$\stackrel{10}{10}$ CONAERG
}

\section{AVALIAÇÃO QUALITATIVA DA USABILIDADE E MOTIVAÇÕES DE USUÁRIOS DE RELÓGIOS INTELIGENTES}

\author{
Gustavo de Andrade Silva (1); \\ Sérgio Tosi Rodrigues (2); \\ Fausto Orsi Medola (3); \\ Luis Carlos Paschoarelli (4);
}

(1) PPGDesign-UNESP, Mestrando em Design

e-mail:gustafy@fc.unesp.br

(2) PPGDesign-UNESP, Livre-docente em Aprendizagem Motora

e-mail:srodrigu@fc.unesp.br

(3) PPGDesign-UNESP, Doutor em Bioengenharia

e-mail:fausto.medola@faac.unesp.br

(4) PPGDesign-UNESP, Livre-docente em Design Ergonômico

e-mail:paschoarelli@faac.unesp.br

\begin{abstract}
RESUMO
Os smart watches finalmente chegaram as mesas de exibição de produtos nas grandes lojas. Porém, pouco se sabe sobre a sua usabilidade e a satisfação de seu usuário. Este estudo investigou qualitativamente as experiências de usuários desse tipo de produto eletrônico afim de compreender suas motivações para compra e experiências reais no seu uso diário. Através de um questionário online, pode-se verificar que os brasileiros que utilizam esse tipo de relógio prezam, principalmente, pela possibilidade de verificar notificações sem retirar o celular do bolso e devido ao incentivo à prática esportiva.
\end{abstract}

\section{ABSTRACT}

Finally, smart watches have arrived at exhibition tables at big stores. However, it is not known its usability and user satisfaction. This study investigated qualitatively user's experience for this kind of electronic to comprehend their purchase motivations and daily usage experience. Thus, through an online questionnaire we could verify that Brazilians use smart watches to mainly check push notifications without taking out their smartphones from their pockets and to motivate them to track their fitness activities. 


\section{INTRODUÇÃO}

Os relógios existem há dezenas de séculos e foram concebidos a partir da necessidade de quantificar fenômenos naturais, como por exemplo, controlar e manipular a produção agrícola da época. O primeiro rascunho desse medidor de tempo surgiu no antigo Egito, onde o precursor do relógio que hoje conhecemos era organizado em dois potes dispostos verticalmente, a água ou areia caía continuamente do pote superior para o pode inferior. Este conjunto de potes, também chamado de clepsidra, continha marcações em seu interior, permitindo que o usuário soubesse, a partir do pote receptor, em que momento do seu dia ou da noite estava. Todavia, somente no século $\mathrm{XV}$ temos o primeiro relógio portátil, o qual era utilizado ao redor do pescoço, estilo um pingente, como um acessório de moda (MARTIN, 2002). Já no século XVI, temos a primeira versão do relógio de pulso, que foi concebido por Robert Dudley em 1571. Este novo formato de relógio foi um presente à Rainha Elizabeth I da Inglaterra.

Martin (2002) comenta que apenas mulheres poderiam utilizar tal acessório, pois os homens que utilizassem o relógio de pulso seriam ridicularizados e caçoados na sociedade da época. O receio era tanto que, segundo Broezk (2004), os homens alegavam preferir usar uma saia a utilizar um relógio de pulso.

Séculos mais tarde, já no período da primeira grande guerra, temos uma inversão no papel do relógio de pulso, neste momento, o produto torna-se um diferencial de guerra, permitindo a sincronização de ataques militares de forma estratégica. Ao final da Primeira Guerra e com a vitória dos aliados, os soldados tornaram-se heróis e eram vistos como exemplo para a sociedade. Por associação, e logo após o retorno desses militares aos seus países de origem, viu-se pela primeira vez homens utilizando relógios de pulso. O mesmo acessório, que até então era considerado "feminino", passaria a ser um acessório masculino.

Nos últimos 100 anos, o relógio de pulso passou por diversas mudanças e aprimoramentos, tanto estruturais quanto conceituais. Contou ainda com diversos formatos, cores, tamanhos e funcionalidades. Mas, somente na década de 1980 ele ficou "inteligente", sendo concebido a partir de um circuito eletrônico e possuindo funções de calendário e caderneta de endereços, por exemplo (MARTIN, 2002).

Mas a "revolução do pulso" (PRADHAM \& SUJATMIKO, 2014) ocorreu somente em 2014, quando surgiram diversas marcas e modelos de smart watches. Nesta fase, os relógios deixaram os laboratórios de pesquisa e chegaram ao consumidor final com grandes aprimoramentos, que permitiram ao seu usuário sentir-se um personagem de ficção científica e utilizar o seu relógio para falar, mandar mensagens de texto, acessar a internet, capturar imagens, conferir postagens de suas redes sociais, ou ainda, receber dicas e monitorar atividades físicas.

Apesar do grande volume de estudos referentes ao uso desse tipo de relógio na área da saúde, devido à ampla quantidade de sensores presentes neste dispositivo eletrônico, pouco se sabe sobre a interação deste dispositivo com o seu usuário ou como ocorre esta interface. Deste modo, da mesma forma que ao longo das ultimas décadas foi estudada a interação entre os seres humanos e os computadores, há a necessidade de compreender os motivos que levam um usuário a colocar um pequeno processador de dados em seu pulso e, assim, saber se este acessório é eficiente, eficaz, confortável e seguro para o seu usuário. Ou ainda, quais as motivações que o leva a adquirir e utilizar esse equipamento em seu dia a dia.

Há vários estudos abordando a temática dos smart watches na literatura. Esses aparelhos também são categorizados como "equipamentos eletrônicos vestíveis", ou seja, um eletrônico que pode ser acoplado à alguma parte do corpo humano. Além disso, são uma nova proposta para manipular a controlar a grande quantidade de informações às quais somos expostos diariamente (BILLINGHURST \& STARNER, 1999).

Raghunath e Narayanaswami (1999) trabalharam na construção de hardware e software a fim de comprimir um computador em algumas dezenas de milímetros, através da miniaturização 
de circuitos eletrônicos, propuseram ainda alguns aplicativos e formas de interação com o usuário. Já Lee e Starner (2010) utilizam o relógio inteligente para verificar a percepção tátil de padrões de alertas para o usuário, enquanto Witt (2014), Pradham e Sujatmiko (2014) buscaram compreender o design e aplicações desses equipamentos no dia a dia das pessoas.

Paralelamente, Chen et al (2014) buscou aprimorar o uso do relógio junto ao celular smartphone de forma a criar um ambiente virtual único e integrado entre esses dois dispositivos eletrônicos. Criaram uma nova forma de interação, na qual uma ação realizada no relógio pode criar uma reação no smartphone e vice-versa.

O estudo de Schirra e Bentley (2015) foi uns dos primeiros interessado em compreender melhor os usuários de smart watches, de forma a caracterizar o seu uso diário. $\mathrm{O}$ foco desta pesquisa foi avaliar os usuários norte-americanos a fim de descobrir porque os mesmos utilizam o dispositivo, o que fazem com o aparelho e quais são os seus problemas de usabilidade no cotidiano.

A partir deste contexto, o presente estudo tem o intuito de caracterizar experimentalmente e qualitativamente as experiências dos usuários de smart watches, identificando as suas motivações para adquirir e utilizar este eletrônico, e a ocorrência de problemas em situações de uso, no cotidiano de usuários brasileiros. Para isso, fundamentamos nossa base teórica nos conceitos de ergonomia, usabilidade e interação humano-computador (IHC), visando utilizar de suas teorias e metodologias para compreender e avaliar os resultados desta pesquisa.

\section{MATERIAL E MÉTODO}

Para a realização do procedimento experimental, buscou-se definir alguns recursos e funcionalidades que um relógio deveria possuir para ser considerado "inteligente" e, assim, atender aos requisitos de participação desta pesquisa. Dessa forma, definiu-se que os relógios de interesse deveriam possuir conectividade não obrigatória com um celular smartphone, possuir a habilidade de exibir notificações de aplicativos, ser apto a conectar-se a internet, executar aplicativos próprios e permitir comunicação com outros usuários através de texto escrito digitado ou falado, voz ou vídeo.

\subsection{Material}

\subsubsection{Material}

Utilizou-se da plataforma de formulários online Google Forms para criar a estrutura do questionário que seria disponibilizado aos participantes através de um hyperlink para acesso e, com o sucesso da coleta, receber as respostas dos participantes.

\subsubsection{Participantes}

Os participantes, desde procedimento experimental, deveriam ser brasileiros e ter idade superior a 18 anos. Além disso, deviam possuir um smart watch que atendesse à definição de relógio inteligente deste trabalho, não importando a marca e modelo. Ademais, o participante deveria ter utilizado o aparelho por pelo menos 30 dias.

\subsubsection{Questionário}

O questionário foi dividido em 4 partes. A primeira parte exibia um texto informativo e convidativo sobre a pesquisa, seus objetivos, os pesquisadores responsáveis e os seus contatos. Já na segunda parte foi apresentado um Termo de Consentimento Livre e Esclarecido, o qual atende à Norma ERG BR 1002, do Código de Deontologia do Ergonomista Certificado (ABERGO, 2003), solicitando de forma obrigatória que o participante assinasse digitalmente, acordando com este TCLE sua participação no estudo. A seguir, apresentou-se o protocolo para identificação, com questões sobre idade, gênero, profissão, marca e modelo do smart watch e seu tempo de uso. 
A quarta parte do questionário continha 24 perguntas, as quais foram organizadas em 4 categorias: motivação para compra, usabilidade, exposição e privacidade, limitações do smart watch, baseado e adaptado de Schirra e Bentley (2015). Das 24 questões, 23 eram obrigatórias, isto é, o participante não poderia prosseguir nem enviar o questionário sem responder todas essas perguntas. Uma única pergunta era opcional, na qual o participante poderia fazer um comentário adicional sobre a sua experiência com o seu relógio inteligente.

Desta forma, a primeira categoria foi "motivação para compra", exibiram-se perguntas para identificar e compreender a razão que levou o participante a adquirir um modelo de relógio inteligente. A segunda categoria, de "usabilidade", apresentou perguntas para listar a experiência e uso do relógio do participante a partir do momento da compra. Já a terceira categoria listou perguntas a fim de compreender se os participantes tiveram alguma preocupação com a exposição gerada pelo relógio, se aparelho ou a interação com o mesmo gerou algum tipo de preocupação em relação à privacidade do participante. $\mathrm{Na}$ quarta categoria propuseram-se perguntas sobre as limitações dos relógios inteligentes de acordo com o uso de seus usuários, ao fim apresentamos 3 perguntas para classificar o relógio inteligente como dispositivo eletrônico, item de moda ou apenas um relógio, além disso, na última questão, expôs-se uma questão optativa, permitindo que o participante pudesse fazer algum comentário adicional sobre o dispositivo eletrônico.

\subsection{Procedimentos}

Esta pesquisa tem caráter qualitativo e visa ser exploratória quanto à relação entre o relógio e o seu usuário. Dessa forma, utilizou-se de um questionário online para medir e identificar o que os usuários de smart watches pensam e sentem a respeito deste dispositivo eletrônico.

Para encontrar participantes para a pesquisa, procuraram-se grupos de discussão sobre o tema nas redes sociais Facebook e Twitter para que pudéssemos convidar e divulgar a pesquisa aos seus membros. Além disso, divulgou-se a pesquisa também aos discentes da Universidade Estadual Paulista "Júlio de Mesquita Filho", campus de Bauru.

Ao receber o convite de participação da pesquisa, o participante deveria clicar sobre o hyperlink do questionário e ler o propósito e objetivo do estudo. A seguir, o indivíduo deveria aceitar o TCLE para participar. Depois dessa etapa, deveria fornecer dados pessoais para que pudéssemos identificar o participante e classificar se o seu relógio era inteligente de acordo com a premissa pré-estabelecida pelos pesquisadores, além de obtermos a marca e modelo do relógio inteligente do participante. O próximo passo foi responder as 24 questões - 22 questões objetivas, uma questão com resposta binária (SIM ou NÃO) e uma questão de múltipla escolha - organizadas em 4 categorias e uma seção aberta para que o participante pudesse fazer comentários adicionais. Ao concluir todas as seções do questionário online, o participante deveria enviar as suas respostas, clicando no botão "Enviar", confirmando a sua participação na pesquisa.

O questionário visava colher dados sobre a experiência do usuário de relógio inteligente independente da marca ou modelo desse acessório. A coleta de dados ocorreu durante 9 dias corridos e ao final deste período obtivemos um total de 35 pessoas interessadas na pesquisa. Entretanto, um desses indivíduos possuía um modelo de relógio que não se encaixa na definição de relógio inteligente pré-definida neste trabalho - o participante possui uma pulseira inteligente com funções tradicionais de relógio e recursos para contar passos, distância percorrida e batimentos cardíacos, mas não há aplicativos - e dessa forma, tivemos que retirar a sua participação da tabulação final dos dados, contabilizando 34 participantes válidos para este estudo. 


\section{RESULTADOS E DISCUSSÕES}

\subsection{Resultados}

Pôde-se verificar que dentre os 34 participantes, 32 eram do gênero masculino e apenas 2 do gênero feminino (Figura 1-A). Os mesmos valores numéricos sobre o gênero dos participantes ilustram o grau de escolaridade dos participadores sendo $32 \mathrm{com}$ ensino superior em curso ou completo e apenas 2 com ensino médio completo (Figura 1-B).

Com relação à ocupação, 15 participantes trabalham ou estudam na área de tecnologia da informação e a profissão dos outros 19 participantes mostrou-se bem divergente, como jornalista, professor, comerciante, publicitário, profissionais de marketing e empresários (Figura 1-C).

Figura 1 - Infográfico para caracterização dos participantes.

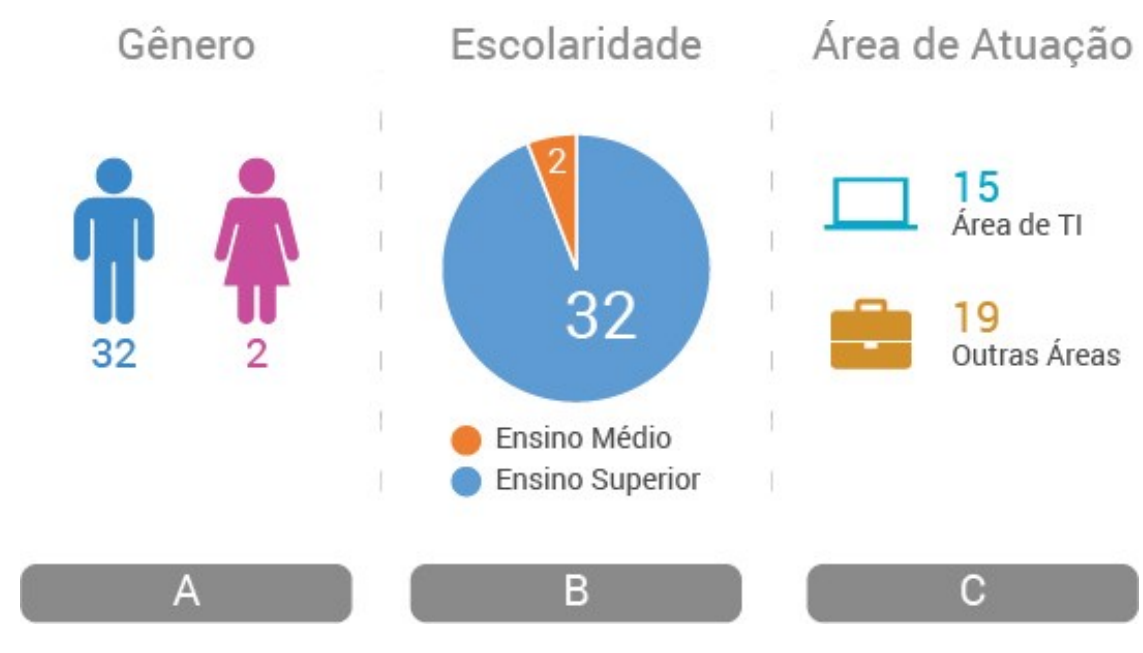

Acerca da representatividade de relógios inteligentes (Figura 2), foram encontrados 19 participantes que compartilharam a suas experiências com o relógio Apple Watch da fabricante Apple (Figura 2-A), 8 participantes com o Samsung Galaxy Gear (S1 ou S2) da fabricante Samsung (Figura 2-B), 4 participantes relataram seu uso com o Motorola Moto 360 da fabricante homônima (Figura 2-C), 2 participantes com o modelo LG Watch (Figura 2-D) e 1 participante com o relógio Huawei Watch da fabricante Huawei Technologies (Figura 2-E). Já para o tempo de uso desses relógios, registrou-se que o extremo inferior foi de 3 meses enquanto que o extremo superior foi de 3 anos.

Figura 2 - Identificação dos relógios inteligentes dos participantes desta pesquisa. A - Apple Watch (Fonte: https://www.dinheirovivo.pt/wp-content/uploads/2016/01/apple-watch-sellingpoints.jpg). B - Samsung Galaxy Gear S2 (Fonte: http://www.samsung.com/uk/consumerimages/product/galaxy-gear/2014/SM-V7000ZKABTU/SM-V7000ZKABTU-79431-0.jpg). C Motorola Moto 360 (Fonte: http://images.indianexpress.com/2015/11/moto360_new1.jpg). D LG Watch (Fonte: http://cdn.androidcommunity.com/wp-content/uploads/2015/08/LG-WatchUrbane-2015-b-752x490.jpg). E- Huawei Watch (Fonte: http://cdn2.pcadvisor.co.uk/cmsdata/features/3624466/huawei_watch_uk_2.jpg). 


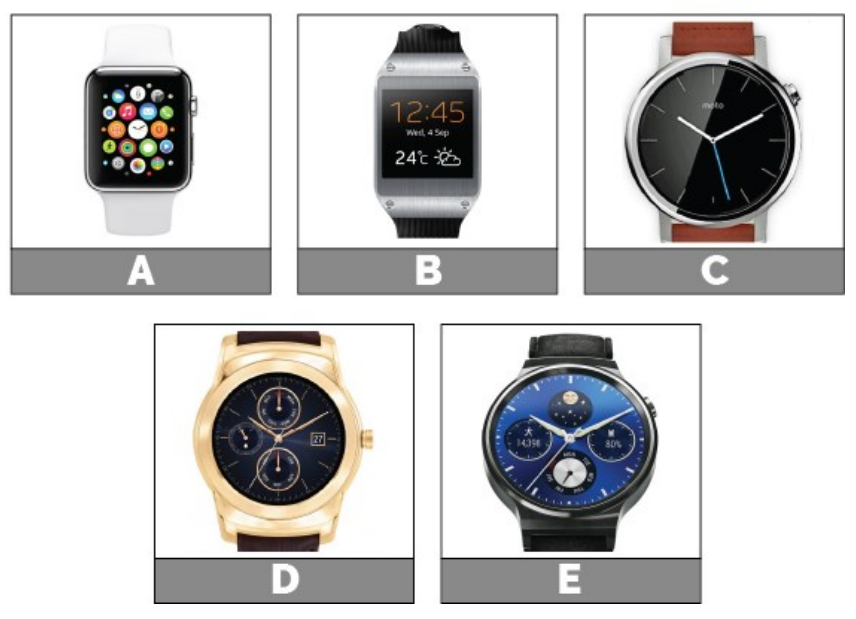

\subsubsection{Motivação para compra}

A grande maioria dos participantes relatou que adquiriu o seu relógio inteligente para facilitar o acesso à informação disponível em seu celular smartphone, reduzindo o esforço muscular de retirar o celular do bolso de suas calças. Ilustra-se essa informação com o depoimento de um dos participantes que disse que adquiriu o seu smart watch "Para estar informado sem ter que tirar o smartphone do bolso", um segundo participante disse "Mostrar as notificações sem pegar o celular" e um terceiro participante exemplificou seu motivo de compra com a funcionalidade de notificações do relógio "Mostrar notificações sem pegar o celular".

Notou-se ainda que a declaração do terceiro participante citado acima foi unanime quando se questionou, o que os usuários mais gostam em seus relógios inteligentes. A grande maioria dos participantes relatou que gosta de receber as notificações de suas redes sociais, novos e-mails, ligações, mensagens de texto (SMS), por exemplo, em seus relógios corroborando com o fato de os usuários preferirem a interação com o relógio para não retirar o celular do bolso. Vale adicionar o comentário de um participante que ressaltou utilizar o seu relógio para verificar as notificações enquanto está no trânsito, indicando que o relógio gera: "[...] facilidade de acesso às notificações do celular, ajudando em situações onde o acesso via celular seria inviável ou difícil como trânsito, reuniões etc.".

O segundo aspecto mais citado como motivação para a aquisição de um smart watch foi a funcionalidade de gerenciar atividades físicas as quais se tornam quantificáveis através de sensores no corpo estrutural do relógio. Esses sensores permitem medir passos, distância percorrida e até batimentos cardíacos a fim de monitorar, sugerir e motivar o usuário a cumprir metas para realizar atividades físicas. Verificou-se esta segunda motivação em vários comentários dos participantes e exemplificamos alguns deles como "[...] medir passos e sono", "[...] motivar a realização de atividades físicas", "[...] auxiliar na prática de esportes" e "[...] monitorar a prática das minhas atividades físicas".

Quando questionados sobre o design do relógio, identificamos que a maioria dos usuários gosta da estrutura e da aparência de seus relógios, porém, notou-se que alguns participantes reclamaram dos aspectos estéticos de seus relógios. Selecionamos os seguintes comentários visando exemplificar o descontentamento de alguns participantes: "Acabamento bonito, mas a caixa do relógio é muito grande"; "[...] a aparência dele [relógio] é uma coisa que não me agrada, é desproporcional e não se parece com um relógio. Porém, por apresentar mais funcionalidades que outros dispositivos no mercado, optei por ele independentemente da beleza."; "Ruim em design, bom em durabilidade"; "A marca é uma das mais acessíveis no mercado. Por isso, o acabamento e design não são tão bons [...]". 


\subsubsection{Usabilidade}

Nesta seção buscou-se identificar as experiências de usuários com os aplicativos nativos para relógios inteligentes, avaliando a satisfação, eficiência e eficácia quando este usuário utiliza um aplicativo próprio para o relógio. Dessa forma, notou-se primeiramente que a maior satisfação dos usuários se encontra no uso de aplicativos para monitorar, incentivar ou sugerir a prática esportiva como se observa nos comentários "[...] monitoro minha atividade física na academia. Ele [o relógio] me força a manter-me ativo principalmente durante o trabalho"; "Utilizo-o para exercícios físicos, para marcar e monitorar o tempo da atividade física [...]"; ou ainda "Gosto muito do aplicativo de exercícios, é o que mais uso.". Entretanto, houve relatos sobre a limitação de hardware do eletrônico vestível, causando lentidão na execução de alguns aplicativos, prejudicando assim, a sua usabilidade como se observa nos seguintes comentários: "[...] o hardware é bem limitado e lento"; "demorado e limitado", além disso vários participantes relataram que os aplicativos para o relógio são limitados e simples.

Indagamos aos participantes a respeito da usabilidade limitada nos relógios, especialmente se esta limitação implicou, em algum momento, no abandono do uso do relógio durante a realização de alguma atividade. A grande maioria dos participantes relatou que esta situação já ocorreu, porém, apesar do motivo para os usuários deixar de utilizar um aplicativo ser divergente, identificou-se que o tamanho diminuto da tela, a escassez de recursos e a ineficiência de aplicativos foram os mais populares como observamos nos seguintes comentários: "[...] a tela do relógio é pequena"; "[...] muito pequena a área de interface"; "Sim, pela tela pequena"; "Sim, devido ao tamanho do display"; "Sim, já deixei de usar devido ao hardware lento"; "[...] minha intenção é receber informação no relógio, se for necessário o meu input, utilizo o smartphone"; "Para ler e-mails em detalhes é necessário usar algo maior que um relógio". Um participante relatou ainda, que depois de longas interações com o relógio, há fadiga muscular ao manter o braço suspenso para manipular o relógio e por este motivo, deixa de utilizá-lo.

Atualmente um dos recursos mais importantes em qualquer dispositivo eletrônico são as formas de comunicação através de texto, voz e audiovisual. Esta operação não poderia ausentar-se nos smart watches, não obstante, observa-se pelas respostas dos participantes que a comunicação é facilitada e mais intuitiva através de textos curtos ou respostas prontas pré-programadas no aparelho. As interações via áudio como chamadas de voz também são utilizadas; alguns participantes utilizam e gostam da funcionalidade, alegando que esta novidade é facilitadora em momentos diversos, enquanto outros participantes relataram que a comunicação auditiva não é tão óbvia: "[...] O smart watch é bom para receber e atender ligações, mas para fazer demora um pouco para se acostumar e não é tão intuitiva". Um dos participantes pontuou que "acha estranho" falar com o seu relógio inteligente em público e outro comentou que evita utilizar as funções de áudio por sentir-se envergonhado.

\subsubsection{Privacidade}

Por um lado, temos o aumento da exposição exacerbada de usuários nas redes sociais ao mesmo tempo em que cresce também a preocupação com a privacidade e o individualismo dos indivíduos. Os smart watches tem funcionalidades próximas as de um celular smartphone e, por isso, deve-se ter preocupações com a privacidade quando se utiliza este aparelho. Estes relógios estão cada vez mais populares e apesar de vários modelos oferecerem um formato similar a um relógio analógico, a maioria ainda parece um gadget de filmes de ficção científica, os quais podem atrair atenção tanto de pessoas à paisana quanto de possíveis usurpadores.

Por isso, perguntou-se aos participantes se os mesmos acreditam que os seus relógios atraem a atenção das pessoas e se eles se preocupam com este aumento da exposição gerada pelos seus relógios quando estão em público. A maioria dos participantes disse que sente que atraem atenção para si quando utilizam os seus relógios inteligentes, notou-se ainda que esta percepção ocorre mais constantemente quando os participantes utilizam 
alguma função nos seus relógios neste local público e, principalmente, quando realizam ou recebem chamadas telefônicas como podemos observar pelos comentários: "Muitas vezes o relógio atrai a atenção das pessoas, principalmente se utilizar para ligação"; "O relógio atrai um pouco a atenção quando ele é utilizado em publico"; "Ao notar que esta se usando-o [o relógio], sim"; "Atrai demais a atenção". Um participante citou que prefere utilizar o seu acessório quando está em ambientes fechados, pois teme assaltos se utilizá-lo nas ruas.

Outro questionamento feito aos participantes foi em relação às atividades que realizadas quando estão em público e quais não realizam em público. Os comentários foram quase unanimes quanto ao uso de aplicativos de mensagens instantâneas e recebimento de notificações no relógio. Por outro lado, as ligações telefônicas e os comandos por voz foram as tarefas mais citadas que os participantes não realizam quando estão em público, pois os participantes preferem utilizar o seu telefone celular, como podemos observar pelos comentários: "Não realizo ligações, talvez evite para não chamar a atenção"; "Não uso o aplicativo de ligação"; "Não utilizo comandos por voz em público"; "Não atendo o telefone pelo relógio".

\subsubsection{Limitações do smart watch}

Acerca das limitações dos relógios inteligentes elucidadas pelos participantes, identificou-se que o maior problema enfrentado pelos usuários do relógio é a pouca duração da bateria, seguida pela demora em executar aplicativos; podemos identificar essas limitações pelos comentários "[...] necessidade de carregar constantemente"; "Tempo da bateria, ter que carregar todo dia"; "[...] limitação na autonomia da bateria"; "Lentidão dos aplicativos"; "[...] velocidade de processamento para aplicativos". A maioria dos modelos de smart watches depende obrigatoriamente de um celular smartphone para obter notificações de aplicativos, conectividade e acesso a internet e, por isso, vários participantes também apontaram a falta de independência do smart watch como uma limitação do aparelho como nota-se nos comentários: "Poderia ser independente"; "Todas as limitações relacionadas ao uso independente do relógio, como internet". Podemos ainda destacar limitações quanto ao fato de o relógio não ser resistente à água e também quanto à execução de alguns aplicativos serem dependentes ou mesmo restritas a uma comunicação entre o relógio e o telefone celular.

\subsection{Discussões}

Os smart watches são equipamentos incríveis e uma prova do grande avanço técnico e científico ocorrido nas últimas décadas. Finalmente, o usuário pode utilizar um acessório há tempos visto em filmes de ficção científica ou de "agentes secretos", de maneira que há anos já eram produtos pesquisados em laboratórios de pesquisa em diversos centros de tecnologia. Porém, ao contrário da ficção, os relógios disponíveis a todo e qualquer consumidor têm limitações, restrições e são passíveis de erros, problemas que interferem diretamente na satisfação de usuários.

Esta pesquisa ajudou na desmistificação da usabilidade e na identificação do motivo para compra de relógios inteligentes por brasileiros, ademais contribuiu ainda para identificar como os usuários utilizam os seus relógios inteligentes no dia a dia, enfrentando problemas reais tanto por fatores adversos de hardware quanto de software.

Desse modo, identificamos que a grande maioria dos usuários que adquire um desses relógios são pessoas envolvidas na área de tecnologia da informação ou ainda entusiastas de novidades tecnológicas. Devido ao alto preço desse tipo de relógio no Brasil, notou-se que o perfil do comprador é de um adulto de gênero masculino e empregado, alguém com uma estabilidade financeira e que tem rendimento acima do salário mínimo brasileiro. Já a motivação para adquirir tal produto, compartilhada pelos participantes, foi a possibilidade de receber notificações do celular smartphone em seu pulso, o que podemos caracterizar como uma extensão visual da tela do celular com menor movimentação muscular nos braços, 
reduzindo assim o esforço necessário para suprir a curiosidade ao receber uma notificação através de algum aplicativo.

Com relação à usabilidade, o principal uso para o smart watch é também o qual motivou a sua compra, ou seja, a maioria dos usuários utiliza o relógio para visualizar notificações de aplicativos. Em segundo lugar, têm-se os aplicativos para monitorar, incentivar e sugerir a realização de atividades físicas. Esses aplicativos fitness usufruem de um conjunto de sensores no corpo estrutural do relógio, garantindo a coleta de dados de batimentos cardíacos, perda de calorias, distância percorrida dentre outros. Os resultados obtidos nesta pesquisa para as formas de uso do relógio de usuários brasileiros são similares aos resultados obtidos na pesquisa de Schirra e Bentley (2015), os quais, na ocasião, encontraram que a maioria dos usuários norte-americanos também utilizam as notificações e aplicativos para cuidar da saúde em seus relógios inteligentes. Em contrapartida, os mesmos autores identificaram em sua pesquisa que os seus participantes relataram sobre a limitação de aplicativos de terceiros, ou seja, os aplicativos produzidos por diversas empresas desenvolvedoras de software eram muito simples e com poucos recursos, o que desmotivaram a continuidade para com o seu uso. Isto corrobora com os resultados encontrados nesta pesquisa, na qual os participantes brasileiros relataram que as suas experiências com aplicativos são, em grande parte, insatisfatórias, pois erram na simplicidade, falta de funcionalidade, problemas de execução e falta de autonomia em relação ao celular.

A limitação do relógio que mais causou desagrado aos seus usuários foi a durabilidade da bateria; segundo os participantes desta pesquisa a bateria tem duração reduzida, especialmente quando utilizam as funcionalidades que dependem da conectividade do relógio com o celular smartphone, funções que gastam mais energia. Mesmo com a otimização no gerenciamento de recursos promovidos pelos fabricantes, nota-se que este é um problema generalizado a todos os eletrônicos que oferecem inúmeros recursos e muita conectividade que tem o alto "custo" de gasto da energia armazenada na bateria. É interessante notar ainda que este fator não foi apontado pelos usuários na pesquisa de Schirra e Bentley (2015), entretanto, os participantes da pesquisa desse autor relataram seu descontentamento com a dependência do relógio inteligente para com um aparelho celular, fato também citado por participantes desta pesquisa. Atualmente, ao contrário da época em que foi realizada a pesquisa do autor acima citado, há disponível no mercado modelos de relógios inteligentes que são completamente independentes de qualquer comunicação com um telefone celular smartphone, modelos que possuem até chip para receber e efetuar ligações e utilizar dados móveis. Mesmo assim, há a prevalência de modelos de relógios inteligentes que dependem da comunicação direta com um aparelho celular.

Apesar da preocupação dos participantes desta pesquisa com relação à exposição pública gerada a partir do uso de relógios inteligentes, poucos citaram ou esboçaram preocupação com a sua segurança ou temor de assaltos. Paralelamente, notou-se uma tendência de uso desse acessório para situações em que seria rude ou inoportuno verificar notificações no aparelho celular, pois, com o relógio, basta que seu usuário gire o pulso para que a tela ilumine-se e mostre as últimas notificações provenientes de aplicativos. Esta situação também foi aferida no trabalho de Schirra e Bentley (2015), na qual a maior parte dos participantes explanou sua liberdade em discretamente olhar as suas notificações em situações nas quais seria inadequado o uso de um smartphone.

\section{CONCLUSÃO}

A partir deste estudo foi possível qualificar as experiências de usuários de smart watches a começar pela sua aquisição, contemplando e listando seu uso através de um questionário online. Assim, podemos inferir também pela dificuldade em encontrar participantes para esta pesquisa, uma vez que este produto ainda é restrito a pessoas com poder aquisitivo mais alto e, consequentemente, ainda desconhecido para a maioria dos brasileiros. 
Os relógios inteligentes são acessórios eletrônicos acoplados ao pulso que permitem inúmeras funcionalidades, entretanto, seus usuários limitam-se a usar poucas atividades como a visualização de notificações, acesso a aplicativos para realizar exercícios físicos a partir dos sensores do relógio e controle multimídia. Cabe aos fabricantes aprimorar o poder de processamento desses dispositivos de pulso a fim de melhorar a velocidade de execução de aplicativos bem como, otimizar e aumentar a durabilidade da bateria para que os usuários possam ter maior autonomia por longos períodos de tempo com seus relógios inteligentes, sem a necessidade de recarregar a bateria deste eletrônico.

De mesmo modo, os desenvolvedores de aplicativos para smart watches precisam compreender melhor os modelos dos relógios inteligentes e suas formas de interação visando criar aplicativos mais interativos, completos e otimizados para tela pequena, eventuais botões e comandos por voz do dispositivo vestível e, principalmente, com conteúdo independente do smartphone, restrição que aumenta o descontentamento do usuário com seu relógio.

Por hora, os smart watches podem ser vistos como uma tela estendida dos smartphones, mas com possibilidades para se tornarem um dispositivo eletrônico recheado de recursos e interatividade, na medida em que os fabricantes e desenvolvedores de aplicativos forem aprimorando e incrementando suas funcionalidades para, assim, deixar de ser visto como um celular de pulso e tornar-se um acessório com suas próprias características como ocorreu com outros aparelhos eletrônicos quando sugiram no mercado, a citar tablets e celulares smartphones. Novos estudos poderão, também, explorar ainda mais as questões físicas e cognitivas da interação entre usuários e smart watches.

\title{
5. REFERÊNCIAS BIBLIOGRÁFICAS
}

\author{
ABERGO. Associação Brasileira de Ergonomia. Norma ERG BR 1002 - Código de Deontologia do \\ Ergonomista Certificado. Disponível em: < \\ http://www.abergo.org.br/arquivos/normas_ergbr/norma_erg_br_1002_deontologia.pdf> [2003]. \\ Acessado em: 08. ago. 2015.
}

BILLINGHURST, M. \& STARNER, T. New ways to manage information. Computer (Volume 32, Issue: 1). 57-64. IEEE. 1999.

BROEZK, J. E. The History and Evolution of the wristwatch. In: International Watch magazine. Disponivel em: http://www.qualitytyme.net/pages/rolex_articles/history_of_wristwa. Acesso em: 18 de Agosto de 2015.

CHEN, X. A., GROSSMAN, T., WIGDOR, D. J., FITZMAURICE, G. Duet: exploring joint interactions on a smart phone and a smart watch, Proceedings of the SIGCHI Conference on Human Factors in Computing Systems, Toronto, Ontario, Canada, 2014.

LEE, S. C. \& STARNER, T. BuzzWear: alert perception in wearable tactile displays on the wrist. In Proceedings of the SIGCHI conference on Human Factors in computer systems. (pp. 433-442). ACM. 2010.

MARTIN, T. L. Time and Time again: Parallels in the development of the watch and the wearable computer. In Werable Computers, 2002(ISWC 2002). Proceedings. Sixth International Symposium on (pp. 5-11). IEEE. 2002

PRADHAN, D., SUJATMIKO, N. Can smartwatch help users save time by making processes efficient and easier?. Final Report-INF 5261. Departament of Informatics. Universitetetet I Olso. 2014.

RAGHUNATH, M. T. \& NARAYANASWAMI, C. User interfaces for applications on a wrist watch. Personal and Ubiquitous Computing 6.1 (2002): 17-30. 2002.

SCHIRRA, S. \& BENTLEY F. R. It's kind of like an extra screen for my phone: Understanding Everyday Uses of Consumer Smart Watches. Proceedings of the 33rd Annual ACM Conference Extended Abstracts on Human Factors in Computing Systems. ACM, 2015.

WITT, S. Wearable Computing: Smart Watches. Fun, Secure, Embed-ded (2014). 